\title{
POLYMORPHISM IN STELOPOLYBIA AREATA (HYMENOPTERA, VESPIDAE)
}

\author{
By Robert L. Jeanne ${ }^{1}$ and Robert Fagen ${ }^{2}$
}

Polymorphism in the social Hymenoptera has been defined as the occurrence within a single colony of two or more distinct morphological forms, or castes, belonging to the same sex (Wilson 1953). Wilson (1953) has pointed out that polymorphism arises out of the occurrence of allometry (differential rates of growth of two parts of the body) over a sufficient range of intranidal size variation to produce morphologically distinct forms at the extremes of this size range. The underlying size variation is due in most cases to differences in larval nutrition (Michener 1961; Wilson 1971). Polymorphism is the morphological adaptation to the functional division of tasks among the members of a colony (Wilson 1953). The most fundamental polymorphism is the separation of the reproductive caste (queens) from the non-reproductive caste (workers). This is followed, most notably in the ants, by the evolution of more or less distinct castes among the workers.

Among the wasps polymorphism appears to be limited to the queenworker dimorphism, where it is most pronounced in the Vespinae (Wilson 197I). Among many of the Polistinae there is no detectable difference, either in size or in morphology, between functional queens and workers (Richards and Richards 195I). The present paper reports the occurrence of complete queen-worker dimorphism in colonies of the polistine species Stelopolybia areata (Say) from Mexico.

\section{Materials AND Methods}

Stelopolybia areata ranges from Mexico south to northern South America (Ducke 1910). The four colonies available for the present study were collected near San Andres Tuxtla in southern Veracruz, Mexico, in January and February 1973. During these months the nests are occupied by adult females only. No brood or males are present. Population size and composition for each colony are given

\footnotetext{
${ }^{1}$ Department of Biology, Boston University, Boston, Massachusetts 02215.

${ }^{2}$ Aiken Computation Laboratory, Harvard University, Cambridge, Massachusetts 02138 .

Manuscript received by the editor February 20, 1974.
} 
Table I. Size and Composition of Adult Populations of Stelopolybia areata colonies.

\begin{tabular}{lccccc}
$\begin{array}{c}\text { Colony } \\
\text { No. }\end{array}$ & $\begin{array}{c}\text { Date } \\
\text { Collected }\end{array}$ & $\begin{array}{c}\text { No. Adults } \\
\text { Collected }\end{array}$ & $\begin{array}{c}\text { No. Queens } \\
\text { Collected }\end{array}$ & $\begin{array}{c}\text { Percent } \\
\text { Queens }\end{array}$ & $\begin{array}{c}\text { Estimated } \\
\text { Total Adult } \\
\text { Population }\end{array}$ \\
\hline 707 & 2 Feb. 1973 & 5884 & 716 & 12.2 & 7000 \\
710 & 15 Jan. 1973 & 7950 & 515 & 6.1 & 8500 \\
725 & 23 Feb. 1973 & 4711 & 257 & 5.5 & 6000 \\
731 & 21 Feb. 1973 & 4227 & 503 & 11.8 & 6000
\end{tabular}

in Table I. A description of the nest of this species and notes on colony cycle are published elsewhere (Jeanne 1973).

In a mass of anaesthetized adults, queens can readily be picked out by virtue of their larger size and distinctive morphology and coloration. Random dissections of queens and workers always showed that the former had well-developed ovaries and full spermathecae, while the latter had undeveloped ovaries and empty spermathecae.

For the present study random samples of queens and workers from each colony were measured and compared. Length of alitrunk was chosen as a measure of body size. This was measured from the front of the humeral collar to the furthest posterior extension of the propodeal valves, as seen from the side. This dimension was preferred as a measure of body size for several reasons. First, the alitrunk is the longest rigid structure of the body, hence is not subject to error due to varying degrees of distension of the gut, or to differences in body position. Second, it is not likely to be an allometric growth center, unlike in the ants, since both queens and workers are winged. Any functional difference in use of wings by workers and queens is less likely to be reflected by allometric differences in size of the thorax than in differences in the wings themselves. Finally, it is preferred to wing length, used in other studies, because wings are subject to fraying at the tips in older workers, making them impossible to measure, and thus biasing the sample against older workers.

The most conspicuous morphologic difference between the two castes is the more bulbous first abdominal tergite (petiole) in the queens (Fig. I). This is best reflected in its width at the widest point, as seen from above; hence this dimension was used as a measure of allometric growth.

All measurements were made on specimens pinned while fresh using an ocular micrometer at a magnification of $25 \times$. 

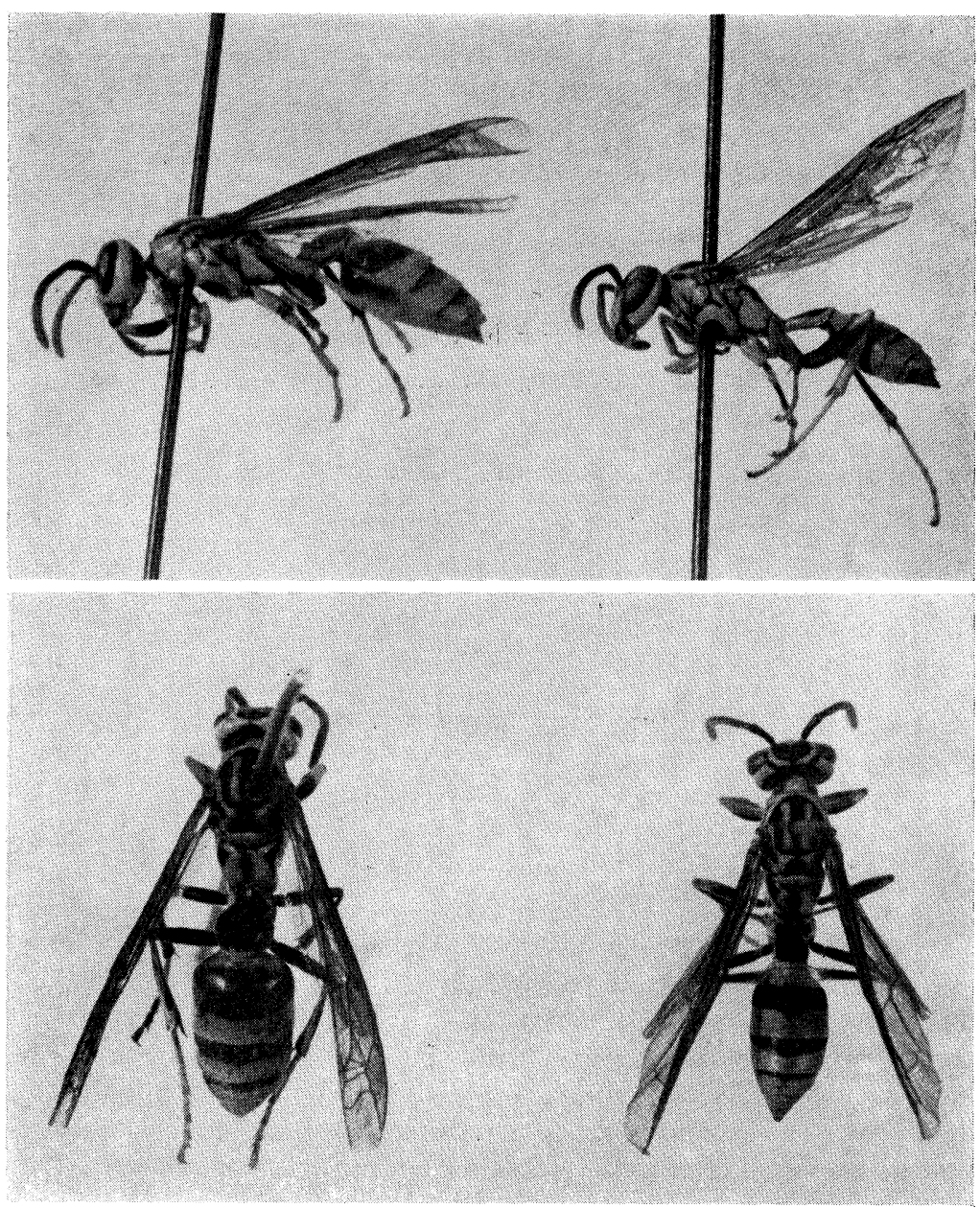

Fig. 1. Stelopolybia areata queen (left) and worker (right). 
Standard methods and tests (Hays 1963) were used for computation and assessment of significance of regression slopes. Lewis (1960) presents techniques for the analysis of intersample differences between regression slopes; we used the following statistic to test the significance of intercaste regression slope differences.

Let $\hat{\mathrm{k}}_{(\mathrm{i})}=$ estimated regression slope for $\mathrm{i}^{\text {th }}$ caste.

$\hat{\sigma}_{(\mathrm{i})}^{2}=$ sample variance in $\mathrm{i}^{\text {th }}$ caste of $\ln$ (tergite width) given In (alitrunk length).

$\hat{\sigma}_{1(\mathrm{i})}=$ sample standard deviation of $\ln$ (alitrunk length) in $i^{\text {th }}$ caste.

$\mathrm{n}_{\mathbf{i}}=$ number of individuals of $\mathrm{i}^{\text {th }}$ caste sampled.

$\mathrm{i}=1$ for workers and 2 for queens.

Under standard assumptions of regression analysis (normality, homeoscedasticity, interindividual independence of measurements) the statistic

$$
\frac{\mathrm{k}_{(1)} \hat{\sigma}_{1(1)} \sqrt{\mathrm{n}_{1}}-\hat{\mathrm{k}}_{(2)} \hat{\sigma}_{1(2)} \sqrt{\mathrm{n}_{2}}}{\sqrt{2} \sqrt{\frac{\mathrm{n} \hat{\sigma}_{(1)}+\mathrm{n}_{2} \hat{\sigma}_{(2)}^{2}}{\mathrm{n}_{1}+\mathrm{n}_{2}-4}}}
$$

has a t-distribution with $n_{1}+n_{2}-4$ degrees of freedom.

\section{RESULTS}

Coloration. Both castes are yellow with brown or black dark markings (Fig. I). The yellow of workers, however, is a bright lemon yellow, while that of queens contains much more brown. The dark markings of workers are mostly black, while in queens they are dark brown, especially on the gaster. Thus, the dark and light coloration of workers is much more contrasting than that of queens.

On average the dark markings are slightly more extensive on the head and thorax of workers than of queens. On the other hand, the dark bands on the gaster are proportionately wider in queens than in workers. The dark band of the second abdominal tergite in workers has a pointed median posterior extension that is lacking in queens.

Body size. Results of the two measurements made are summarized in Table II. There is no overlap in size (length of alitrunk) of queens and workers in any of the colonies; thus the two castes are 
Table II. Queen/Worker Dimorphism in Stelopolybia areata.

A. Length of Alitrunk

\begin{tabular}{cccccccc}
$\begin{array}{c}\text { Colony } \\
\text { No. }\end{array}$ & $\mathrm{N}$ & $\begin{array}{c}\text { Queens } \\
\text { Average }\end{array}$ & Range & $\mathrm{N}$ & Average & Range & Queens/ \\
\hline 707 & 45 & 4.22 & $4.02-4.37$ & 45 & 3.63 & $3.29-3.75$ & 1.16 \\
710 & 49 & 4.10 & $3.83-4.29$ & 60 & 3.57 & $3.29-3.75$ & 1.15 \\
725 & 23 & 4.13 & $4.02-4.29$ & 50 & 3.68 & $3.41-3.83$ & 1.12 \\
731 & 50 & 4.19 & $3.98-4.33$ & 50 & 3.68 & $3.33-3.83$ & 1.14
\end{tabular}

B. Width of First Abdominal Tergite

\begin{tabular}{|c|c|c|c|c|c|c|c|}
\hline \multirow{2}{*}{$\begin{array}{l}\text { Colony } \\
\text { No. }\end{array}$} & \multirow[b]{2}{*}{$\mathbf{N}$} & \multicolumn{2}{|c|}{ Queens } & \multirow[b]{2}{*}{$\mathbf{N}$} & \multicolumn{2}{|c|}{ Workers } & \multirow{2}{*}{$\begin{array}{l}\text { Queens/ } \\
\text { Workers }\end{array}$} \\
\hline & & Average & Range & & Average & Range & \\
\hline 707 & 45 & 1.60 & $1.34-1.72$ & 45 & 0.94 & $0.88-1.00$ & 1.70 \\
\hline 710 & 49 & 1.52 & $1.30-1.68$ & 60 & 0.95 & $0.84-1.00$ & 1.60 \\
\hline 725 & 23 & 1.49 & $1.42-1.57$ & 50 & 0.95 & $0.88-1.00$ & 1.57 \\
\hline 731 & 50 & 1.58 & $1.42-1.76$ & 50 & 0.93 & $0.88-1.00$ & 1.69 \\
\hline
\end{tabular}

completely dimorphic with respect to this character. This is shown graphically in Fig. 2, where size-frequency distribution data for three of the colonies are grouped. (Colony $7 \mathrm{ro}$, whose queens and workers are smaller than average, is omitted from Fig. 2 because its smallest queens overlap in size with the largest workers of two of the other colonies, obscuring the bimodality that exists within colonies.) The ratio of average length of alitrunk in queens to that in workers ranges from I.I2 to 1.16 for each of the four colonies sampled, with an overall average of $\mathrm{I} .15$.

Allometry. The width of the first abdominal tergite is proportionately much greater in queens than in workers. This is evident in the large queen/worker ratios with respect to this dimension (Table II). The regression of the width of the first abdominal tergite on alitrunk length has been computed for queens and workers of each of the four colonies, and the equilibrium constants ( $k$, or slope of the regression line) are presented in Table III.

In all colonies the allometry of the worker caste is negative. For queens this shifts to strongly positive in all colonies except 725 (where small sample size may have biased the result). The intranidal differences in $k$ for queens and workers are significant at the $1 \%$ level 
I6o

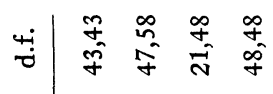

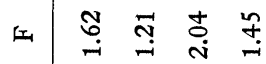

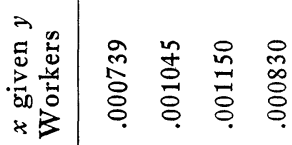

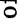

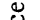

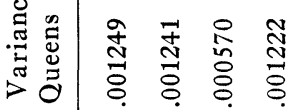

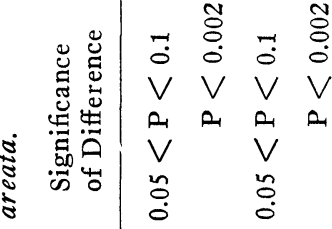

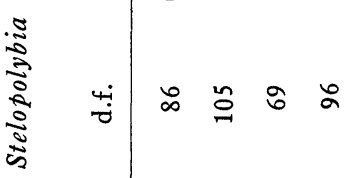

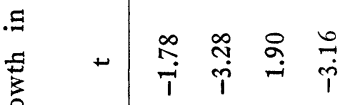

0

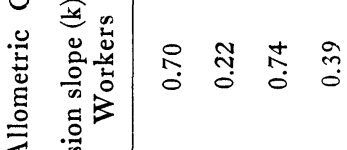

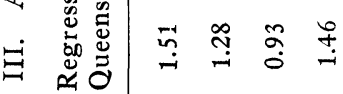

한 


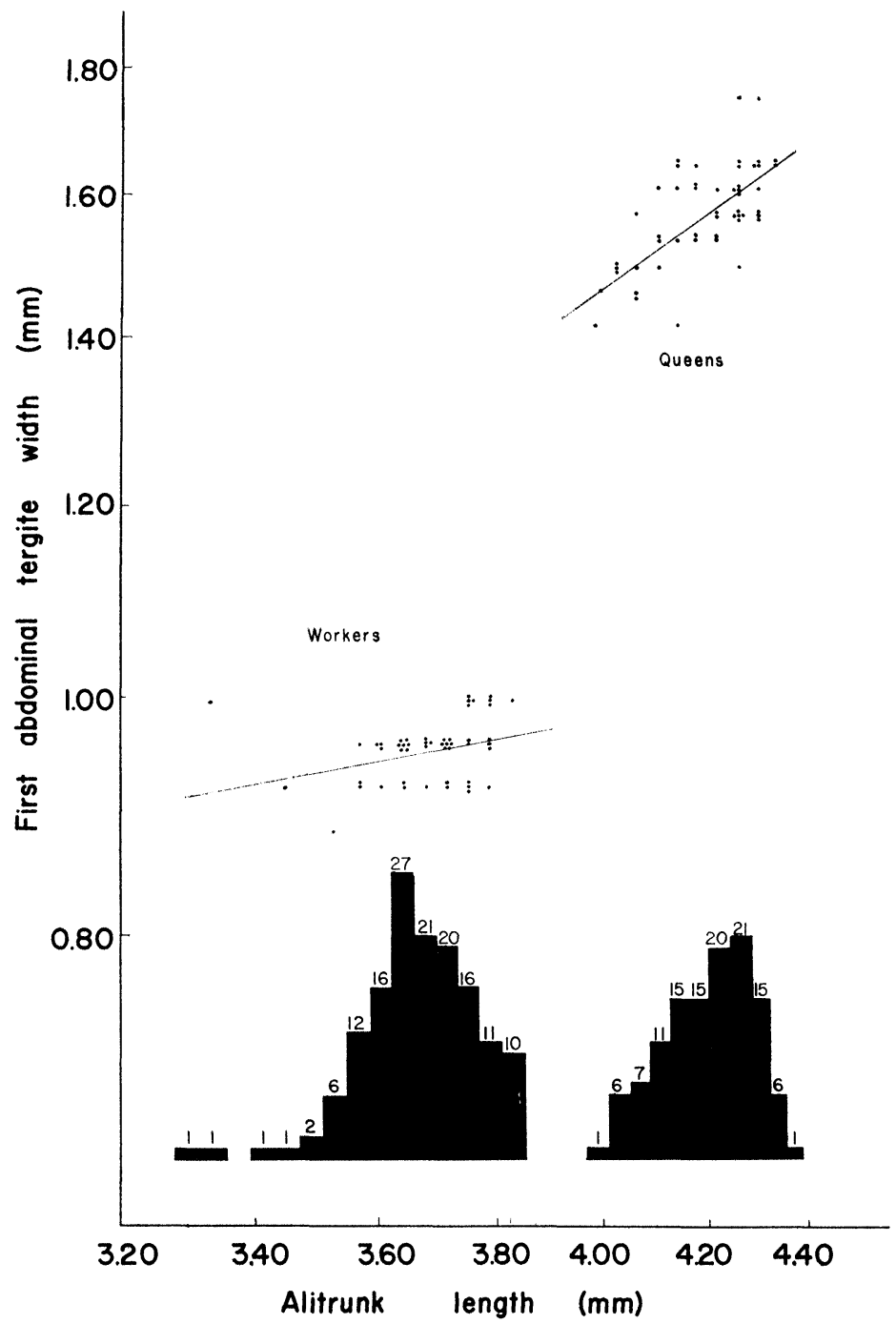

Fig. 2. Intranidal allometry and complete dimorphism in Stelopolybia areata. Log-log plot of first abdominal tergite width against alitrunk length for members of colony 731. Computed regression lines are shown. Bar graph gives frequency distribution of alitrunk length among queens and workers of three colonies $(707,725,731)$. Numbers at the top of each bar give number of individuals. 
for two colonies, and not quite significant at the 5\% level for the other two (Table III).

A log-log plot of allometry in colony $73 \mathrm{I}$ is shown in Fig. 2. The lack of alignment of the computed linear regression lines suggests that the dimorphism in this species may have arisen out of triphasic allometry with a dropping out of intermediates (Wilson I953).

\section{Discussion}

The positive allometric growth of the first abdominal tergite in queens probably has an adaptive significance for the reproductive role of this caste. The expanded width of this segment reflects a general increase in size of the gaster (Fig. I ), which is most easily explained as an adaptation to accommodate the well-developed ovaries. Blackith (1958) found a similar increase in body proportions toward the posterior of queens compared to workers for two species of Vespula.

The negative allometry of the first abdominal tergite in workers must have other causes, however. It is possible that the narrower, more petiole-like first segment in workers may permit a greater maneuverability of the gaster and hence the sting, a feature that could in turn be interpreted as an adaptation to the role of workers in defense. Presumably the evolutionary divergence of the two castes with respect to this character reflects an almost complete functional sparation of the reproductive and defensive roles.

The variance of the width of the first abdominal tergite given the length of the alitrunk is higher than that for ants (Wilson r953). It resembles more closely the variance for certain halictine bees (Knerer \& Atwood 1966). These differences may reflect a genetic component to the variability observed. In mononogynous ants all the workers of a colony are offspring of a single queen, and quite likely of a single male. In $S$. areata, however, since the colonies are polygynous, the individuals sampled do not all have the same parents, and thus represent a larger pool of genetic variability.

A comparison of the degree of polymorphism shown by $S$. areata with that of other vespids is of interest, though difficult because of the lack of comparability of measurements used from one study to the next. The Vespinae are biometrically the best known social wasps (e.g. Wright, Lee, and Pearson 1907; Thompson, Bell, and Pearson I910, I9I I ; Blackith 1958). They also show the greatest degree of polymorphism. Blackith's results for Vespula germanica and $V$. rufa are probably typical (Blackith 1958 ). For the sake of comparison let 
us choose his measurement of thorax width as a measure of body size. Confidence that this indeed is a good indication of body size is gained from the fact that the cube of the queen/worker ratio for this dimension closely approximates the ratio of the reduced body weights of the two castes. The ratio of queens to workers for this character is 1.37 and $\mathrm{I} .34$ for $V$. germanica and $V$. rufa, respectively, and compares with I.I5 queen/worker ratio for alitrunk length for $S$. areata (Table IV). Thus there is considerably greater separation of queens and workers with respect to average body size in Vespula rufa and $V$. germanica than in S. areata.

In the subfamily Polistinae the degree of polymorphism appears to range from virtually none to the degree of dimorphism shown by $S$. areata. Almost nothing has been done biometrically with the subfamily, with the exception of Richards and Richards' analysis of certain characters in some of the South American species (Richards and Richards 195I). The primary aim of Richards and Richards' analysis was to find reliable morphological characters that could be used to distinguish queens from workers. Queens were defined as having sperm in the spermatheca. In some species the two castes differed most significantly in the number of hamuli, while in others wing length, vertex width, mesonotum length, or shape of the first abdominal tergite were more reliable. Of the characters measured by Richards and Richards probably mesonotum length comes closest to being an indicator of body size. At any rate, it is most comparable to alitrunk length, used in the present study. If we use as an index of queen/worker dimorphism the ratio of average mesonotum length for queens to that for workers, the two species analyzed by Richards and Richards have values considerably below the ratio of queen to worker alitrunk length for $S$. areata (Table IV). Small but significant differences with regard to at least one character were found by Richards and Richards to exist between queens and workers in Polybia bistriata, P. occidentalis occidentalis, Protopolybia pumila, P. minutissima, Brachygastra scutellaris, and Polistes canadensis (Richards and Richards 195I).

\section{Conclusion}

Stelopolybia areata thus appears to have achieved a high degree of queen/worker dimorphism relative to other species of Polistinae that have been studied. Other species in the genus have been mentioned in the literature in this connection. Queens of $S$. flavipennis, for 
I 64

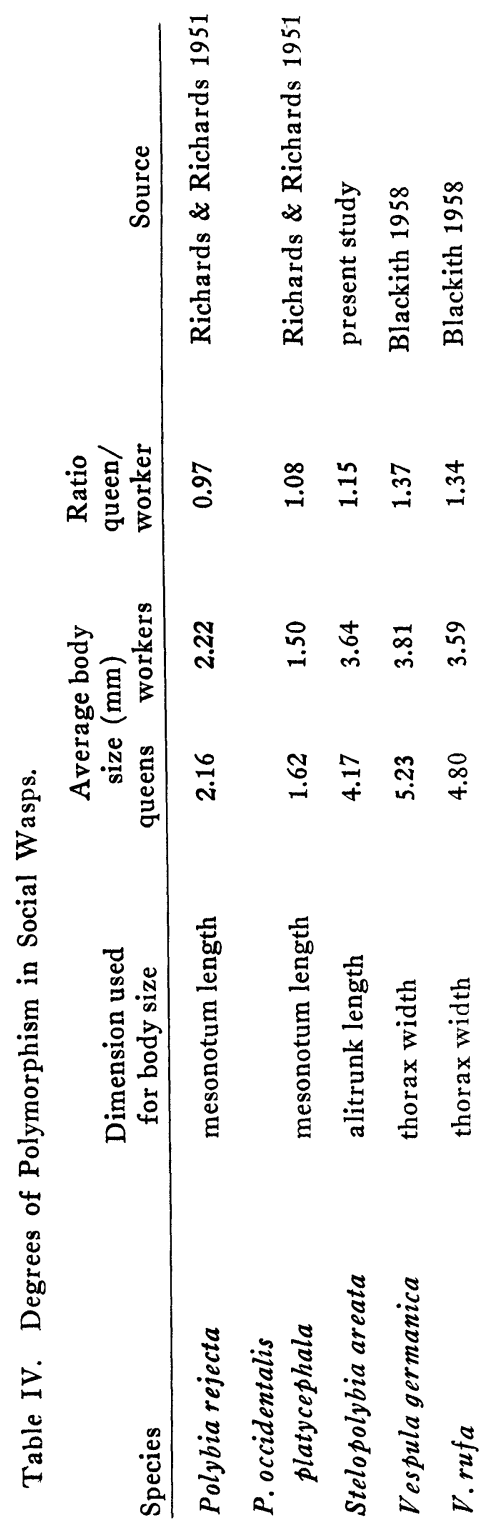


example, figured by Evans and Eberhard (1970), have an enlarged petiole. Both of these species form large colonies. This is consistent with the conclusion of Richards and Richards (195I) that species which form larger colonies tend to have more distinctive queens.

\section{Acknowledgments}

We are grateful to Dr. Antonio Lot Helgueras of the Department of Botany, Universidad Nacional Autonoma de Mexico, for making available the facilities of the Estación de Biología Tropical 'Los Tuxtlas' and to members of the staff of the Estación for their help. Dr. José Sarukhán, Dr. Raul MacGregor, Dr. Arturo GomezPompa, and Dr. Carlos Márquez Mayaudón, all of UNAM, also deserve thanks for their help in making arrangements for the field work. Mr. Mark Winston helped in the field and with the measurement of the wasps. Dr. O. W. Richards kindly confirmed the identification of the wasp. Dr. E. O. Wilson provided helpful comments and advice in the preparation of the manuscript. The research was supported by the National Science Foundation (GB-336ra) and by the Boston University Graduate School (GRS-3O3-BI).

\section{REFERENCES}

BLACKITH, R. E.

1958. An analysis of polymorphism in social wasps. Insectes Sociaux, $5(2): 263-272$.

DUCKE, A.

1910. Révision des guêpes sociales polygames d'Amérique. Ann. Mus. nat. Hungarici, $8: 449-544$.

Evans, H. E. and M. J. W. Eberhard

1970. The wasps. University of Michigan Press, Ann Arbor, vi + 265 pp.

HAYs, W. L.

1963. Statistics. Holt, Rinehart, and Winston, New York, xvi +719 pp.

JEANNE, R. L.

1973. Aspects of the biology of Stelopolybia areata (Hymenoptera: Vespidae). Biotropica, 5 (3) : 183-198.

Knerer, G. and C. E. Atwood

1966. Polymorphism in some nearctic halictine bees. Science, $152(3726)$ : 1262-1263.

LEWIS, D.

1960. Quantitative methods in psychology. McGraw-Hill, New York, xii +558 pp.

Michener, C. D.

1961. Social polymorphism in Hymenoptera. Symposium of the Royal Entomological Society of London, 1: 43-56. 
RichaRdS, O. W. AND M. J. RichaRdS

1951. Observations on the social wasps of South America (Hymenoptera; Vespidae). Trans. Roy. Entomol. Soc. Lond., 102: 1-170.

Thomson, E. Y., J. Bell, and K. Pearson

1910. A second cooperative study of Vespa vulgaris. A comparison of the queens of a single nest with queens of a general population. Biometrika, $7:$ 48-63.

1911. A third cooperative study of Vespa vulgaris. Comparison of queens of a single nest with queens of the general population. Biometrika, 8 : 1-12.

WiLson, E. O.

1953. The origin and evolution of polymorphism in ants. Quart. Rev. Biol., 28 (2) : 136-156.

WiLson, E. O.

1971. The insect societies. Belknap Press, Harvard University Press, Cambridge, Mass., $\mathrm{x}+548$ pp.

Wright, A., A. Lee, and K. Pearson

1907. A cooperative study of queens, drones and workers in Vespa vulgaris. Biometrika, $5: 407-422$. 

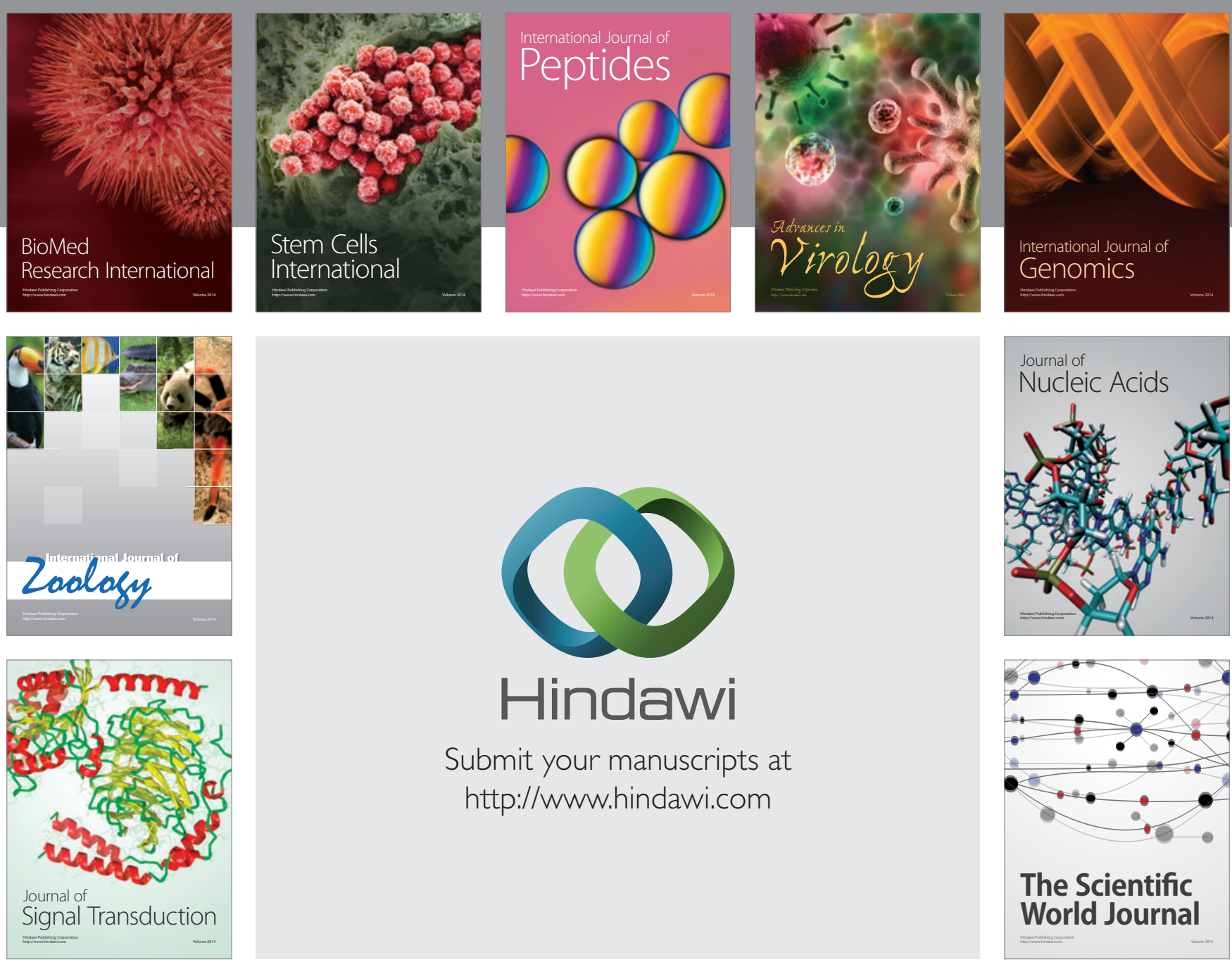

Submit your manuscripts at

http://www.hindawi.com
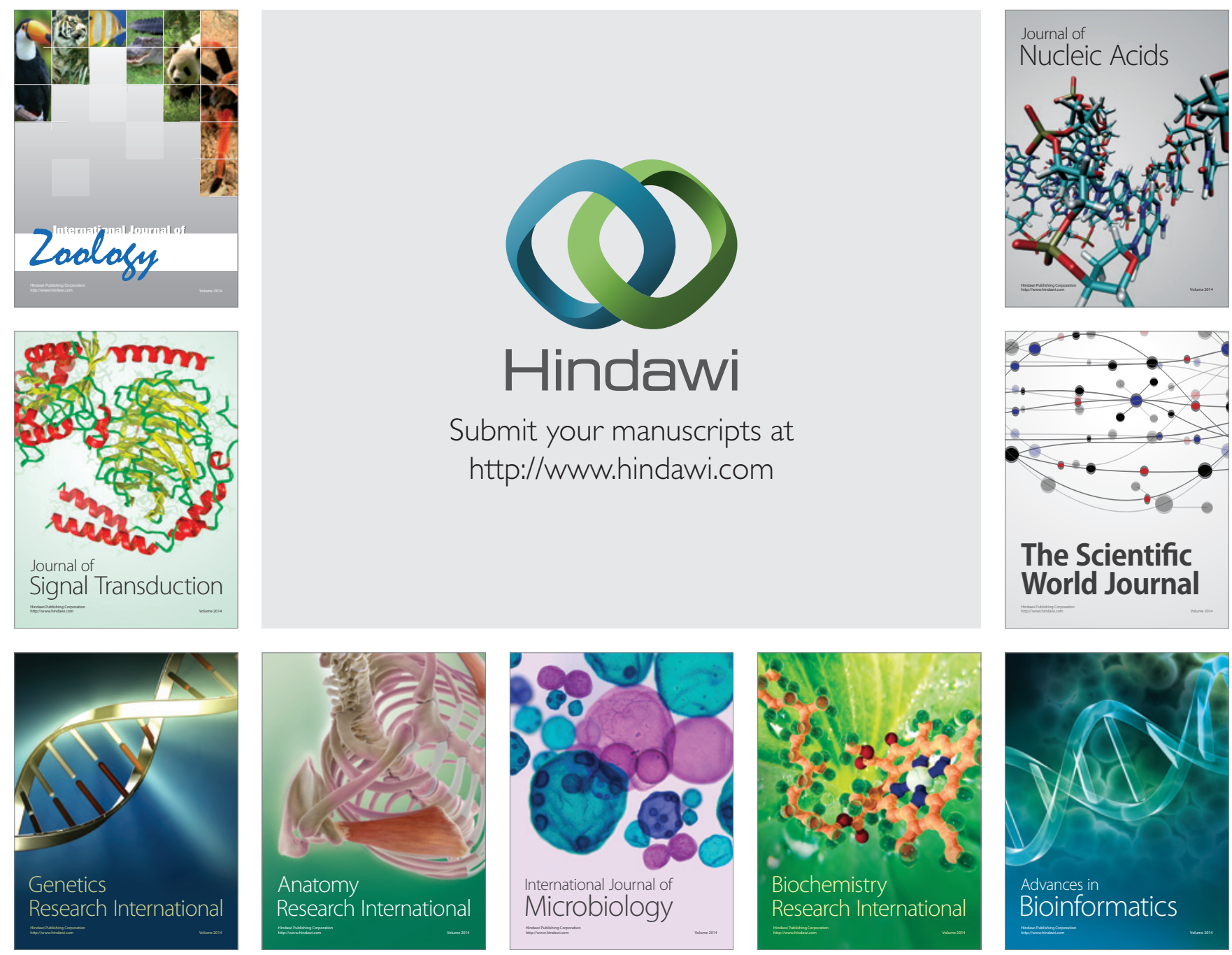

The Scientific World Journal
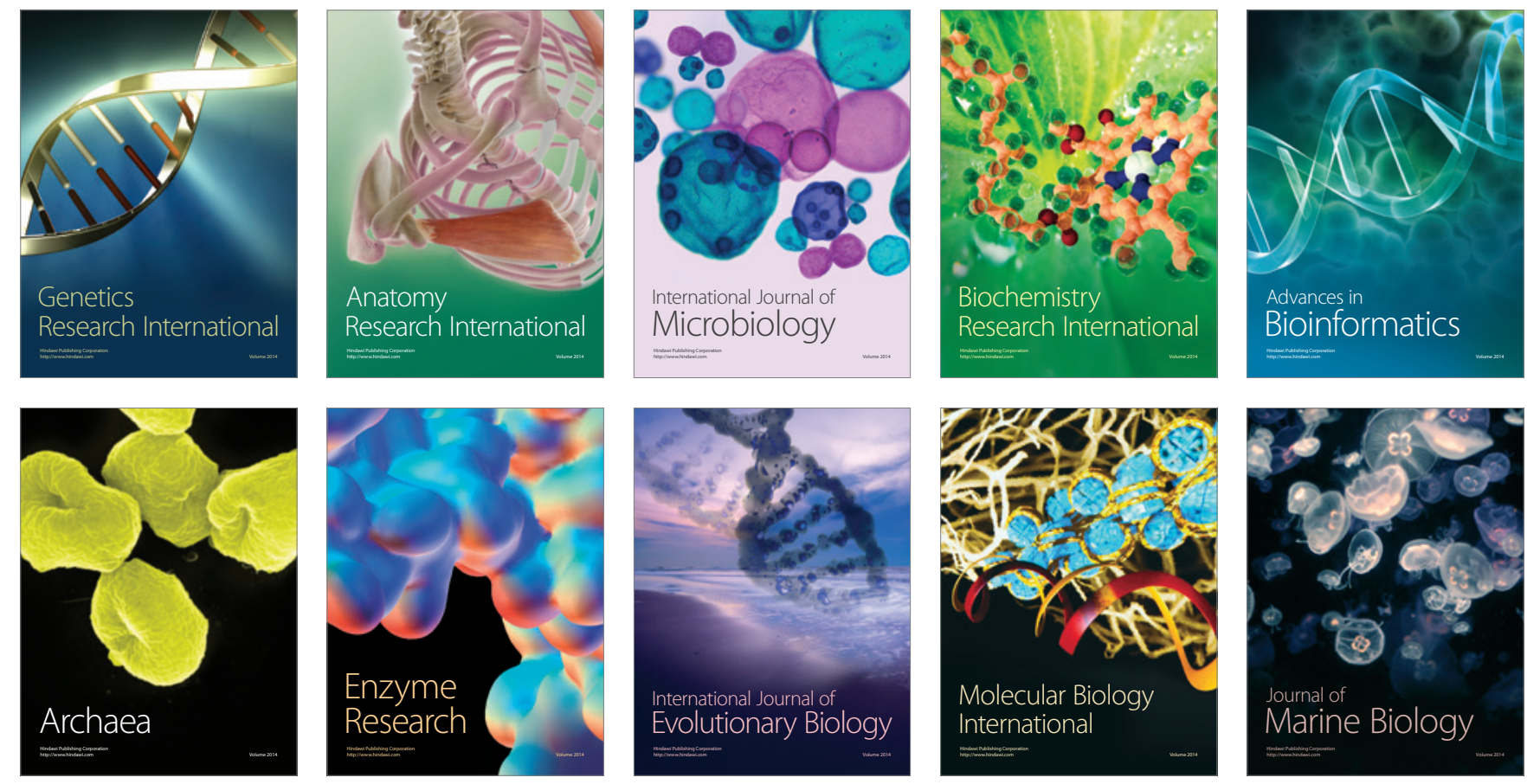